\title{
DIRECTIONS TO IMPROVEMENT SELECTION-TECHNOLOGICAL FEATURES OF CATTLE AYRSHIRE BREED
}

\author{
Vladimir Trukhachev, Sergei Oliinyk, Nikolai Zlidnev \\ Stavropol State Agrarian University, Russia \\ segwan@rambler.ru
}

\begin{abstract}
The average annual dairy productivity of the North Caucasian population of Ayrshire cattle breed $(\mathrm{n}=$ 550 cows) is 6.0-6.2 thousand kilograms of milk, the age of cows is between 3 and 8 years, and the calving interval is usually not more than 400 days. A linear assessment of the exterior of the cows showed that the benchmarks for major groups of characteristics (body volume, ribs angularity, leg quality, quality of udder, animal species) were within the limits of 5.00-5.90 (points). The main shortcomings of the exterior are related to the deterioration of the technological properties of udder after 2 calvings, and the global assessment of some characteristics is reduced: suspensory ligament of udder, depth and height of the udder attachment. The milk quality indicators derived from the average data of the individual dairy productions of cows were: fat $-3.98 \mathrm{~g} \%$, protein $-3.23 \mathrm{~g} \%$, somatic cells -285 thousand C/ML, which corresponded to the breeds of animals and the Russian quality parameters for the "high-class" milk category. The prospective selection direction is determined to produce individual bull-makers to improve the groups of features: the quality of legs and the quality of udder.
\end{abstract}

Keywords: Ayrshire cattle breed, linear assessment, cow exterior, milk quality.

\section{Introduction}

The most important aspect of the improvement of breeding in dairy herding is the creation of consolidated, homogeneous herds of cattle, with high dairy productivity, fat and protein levels in milk, resistant to different diseases and adapted to industrial feeding and maintenance technologies. One way to improve the genotype of dairy cattle in Russia is to increase the relative weight of Ayrshire breed, which rightly belongs to the best cultural dairy species of the world $[1 ; 2]$.

The North Caucasian population of Ayrshire cattle is characterized by stable and high dairy productivity parameters within 6.0-6.2 thousand kilograms of milk and content of fat and protein in milk, respectively 3.98 and 3.23 (g \%), unpretentious to feeding and maintenance conditions, resistant to various communicable diseases. Dairy cattle of Ayrshire breed according to their genotypic and productive characteristics satisfies the production needs of national milk producers and is used in many regions of Russia [4-6].

At the same time, the development of dairy herding necessitates the creation of modern, consolidated and homogeneous exterior-constitutional signs.

The purpose of the research was to develop ways to improve the breeding and technological characteristics of Ayrshire cattle breed.

\section{Materials and methods}

The research materials were zooveterinary documentation for the North Caucasian population of Ayrshire cattle breed ( $n=550$ cows), as well as cows of the first (103 heads) and third (103 heads) lactation.

The dairy productivity of cows and the quality of milk have been determined in accordance with the national regulatory requirements $[1 ; 2]$.

A linear assessment of the body was carried out of cow-heifers (I lactation) and adult cows (III lactation) in accordance with the national requirements (on a 9-point scale) [7]. The assessment of the exterior and type of cows is carried out on a set of characteristics of the 2-3 months of the first lactation, and is set on a number of features characterizing the volume of the body (OT), the expression of the dairy type (MT), the quality of the legs (H), the udder (B) and the general type of the animal (OB). Each of the signs is evaluated according to a 100-point system.

The general assessment of cows by exterior and type is determined by the formula:

$$
\mathrm{O}=\mathrm{OT} \times 0.10+\mathrm{MT} \times 0.15+\mathrm{H} \times 0.15+\mathrm{B} \times 0.40+\mathrm{OB} \times 0.20
$$

The assessment of the exterior of cows is carried out on five sets of indicators, each of which has been assessed in terms of the following. 
1. The volume of the body (OT) is examined by 3 indicators: rump length, breast width, and breast depth.

2. The dairy type (MT) is determined by angularity of robs.

3. The quality of the legs $(\mathrm{H})$ is assessed by: back legs, angle of hooves.

4. Quality of udder (B)-attachment of udder in front, height of udder attachment, width of udder attachment, supporting ligament, depth of udder, placement of front nipples, length of front nipples, position of rear nipples.

5. The general view of the animal (OB) is the angle of inclination of rump, width of rump, growth, muscles.

The sum provides an animal rating on 18 indicators, each of which is estimated at 1 to 9 points.

Specific gravity in the general assessment of the volume of the body (OT) is 0.10 . That is why this set of features may have a maximum score of 1.5 points. The share of the total evaluation of the dairy type (MT) and the quality of the legs (H) is 0.15 respectively, and hence the maximum score of the corresponding complexes is 2.25 . The overall assessment of the quality of udder (B) is 0.40 , the maximum rating is 6 points; the overall rating of the animal $(\mathrm{OB})$ is equal to 0.20 , hence the maximum score is 3 points.

On the basis of the body of the maximum rating, the animal can get 15 points, and each set of features in the overall evaluation has its own weight [8].

\section{Results and discussion}

A linear assessment of the exterior of cows showed that the benchmarks for the major groups of characteristics (body volume, ribs angularity, leg quality, quality of udder, animal species) were within the limits of 5.00-5.90 points (Figure 1).

The most notable technological traits with positive breeding $(>5)$ are the following: the location of the back nipples, the thickness of the plus bone.

The basis of a neutral average rating of 5 points is: the characteristics of the movement, growth, inclination of rump, length of front nipples, length of rump, depth of udder, rear legs, side view, and angularity of ribs. The ratings below 5 points and need for a breeding improvement are: the width and angle of the rump, placement of the front nipples, supporting ligament, width and height of the udder attachment, attachment of the udder front, state of the hock joint, angle of the hooves, rear legs, side view, breast width.

The analysis of the actual and desirable modelling profile of the first Ayrshire breeds showed that, in order to achieve the desired parameters, it would be necessary to raise the point ratings by the breeding grounds for the following: rump length is to improve by $1.3(+1.3)$; breast width is +1.7 ; breast depth is +1.5 ; angularity of ribs is +1.9 ; rear legs, rear view are +1.2 ; rear legs, side view are +1.5 ; angle of the hooves is +1.7 ; state of the hock joint is +2.3 ; thickness of the plus bone is +2.7 ; udder front attachment is +2.9 ; udder height attachment is +2.5 ; udder width attachment is +2.2 ; supporting bundle is +2.5 ; depth of udder is +2.3 ; placement of the front nipples is +2.3 ; length of the front nipples is +1.1 ; location of the back nipples is +0.4 ; tilt angle of rump is +1.6 ; width of rump is +1.9 ; growth is +2.3 ; muscles are +0.8 ; fatness is +0.8 .

Analysis of the comparative graphs-columns of the linear assessment of cow-heifers (I lactation) and adult cows (III lactation) of Ayrshire breed (Figure 2) shows that with a sufficiently high correlation between the two curves-the coefficient was $\mathrm{R}=0.60$, there is still some improvement in the exterior characteristics in the process of cow breeding, so the point rating of adult cows on most grounds characterizes animals with more advanced body-related features that are technologically important for milk production. However, on some grounds, that are critically low at a young age, the udder of the front, the angle of the hoofing of the ligaments and the placement of the front nipples are still at the same level or deteriorating.

In general, there is a natural positive trend in scoring rates for adult cows in relation to cowheifers to such indicators: the rating of "breast width" is increased by 1.3 points; breast depth -1.2 ; angularity ribs-0.6; rear legs in the rear-to 0.1 and rear legs of the side-by 0.9 ; angle of hooves is 1.0 ; state of the hock joint at 0.8 ; the thickness of the plus bone is 0.2 ; attachment of udder the front to 0.2 ; anchorage height udder-0.3; attachment width of udder-0.5; supporting bind -0.2 ; placement of the 
front nipples-0.1; length of the front nipples is 0.8 ; sacrum inclination is 0.7 ; width of the sacrum is 0.9 ; hight- 0.2 ; muscles- 0.7 ; fatness-0.6; character of the movement-to 0.1 and temperament-is 0.2 .

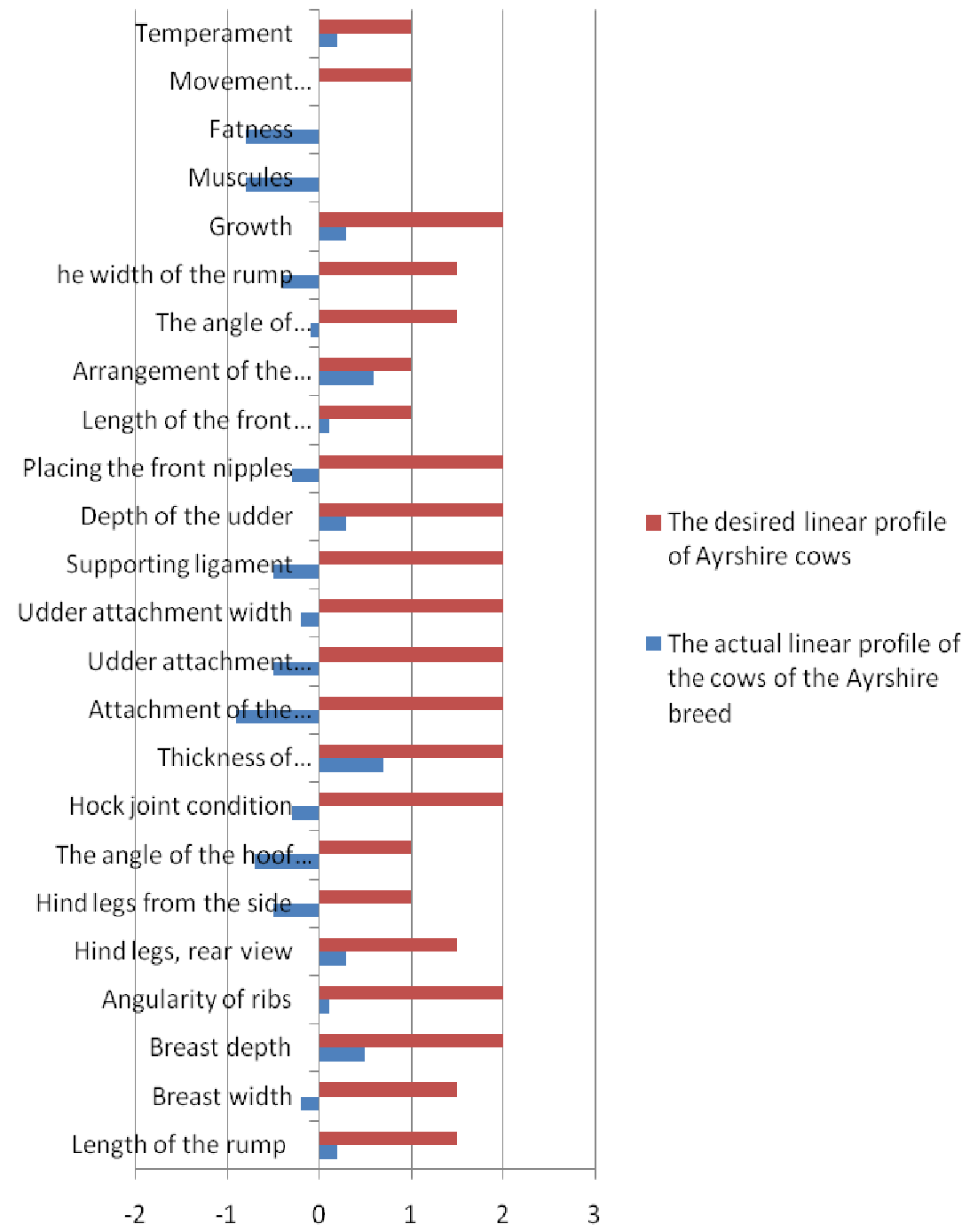

Fig. 1. Bar chart of the actual and desirable model (production type) of the linear assessment of the cows-heifer of Ayrshire breed

Analysis of the standardized distribution of cow-heifer of Ayrshire breed according to a Point rating (Table. 1 , the interval-0.5 point) indicates that the largest in the number is the middle class (7.08.5 points), but the presence of cows with a lower-more than 7 points and a higher point rating is over 9 points. The group of cow-heifer from 8 to 9 points is promising. The presence of the most numerous groups with 7.0-8.5-point assessment shows a balanced system for the expansion of the repair of juveniles and the organization of a sufficient, efficient milk production system in the Ayrshire cattle population.

Table 1

Distribution of cow-heifer (I lactation) by class of rationing according to linear scoring

\begin{tabular}{|l|l|l|}
\hline Number of animals & Points for exterior & \% of total estimated animals \\
\hline 7 & $6.82 \pm 0.06$ & 6.8 \\
\hline 19 & $7.29 \pm 0.03$ & 18.5 \\
\hline 23 & $7.76 \pm 0.03$ & 22.3 \\
\hline 18 & $8.23 \pm 0.03$ & 17.5 \\
\hline 14 & $8.66 \pm 0.04$ & 13.6 \\
\hline 13 & $9.39 \pm 0.06$ & 12.6 \\
\hline 9 & $10.56 \pm 0.12$ & 8.7 \\
\hline
\end{tabular}


The comparison of the results of the average linear assessment of the exterior characteristics of the cow-heifers and the adult cows of the Ayrshire breed showed, in the process of growing Ayrshire cattle, that there is a natural tendency to increase the scoring of adult cows as compared with the cowheifer in relation to body articles that characterize the linear and growth parameters-growth, width and depth of breast, angularity of ribs, width of sacrum.

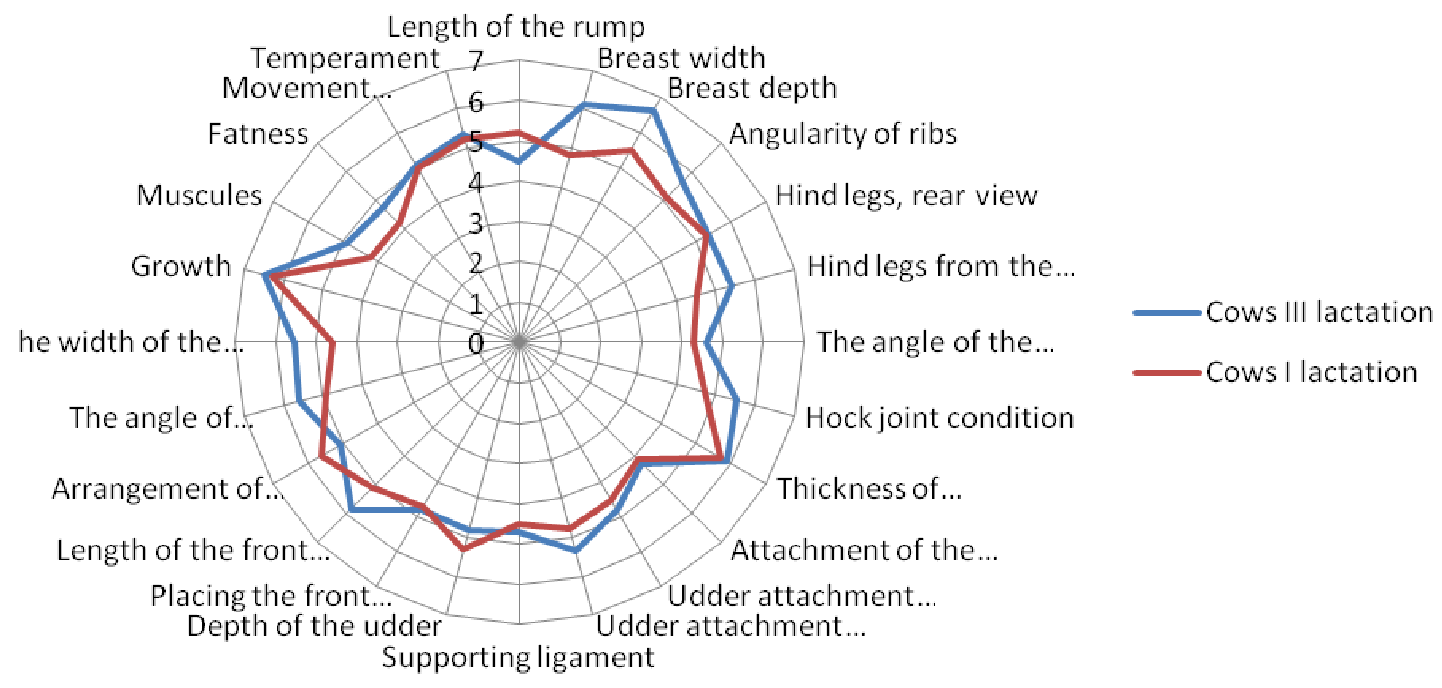

Fig. 2. Comparative graphs-histograms of linear assessment (scoring) of cow-heifers (I lactation) and adult cows (III lactation) of Ayrshire breed, correlation coefficient, $R=0.60$

The main shortcomings of the exterior are related to the deterioration of the technological properties of udder after 2-nd calving, and the global assessment of some characteristics is reduced: supporting ligament of udder, depth and height of udder anchorage. In the selection of oxen, attention should be paid to improving the udder and limb conditions of cows.

The milk quality indicators derived from the average of the individual dairy productions of cows were: fat $-3.98(\mathrm{~g} \%)$, protein $-3.23(\mathrm{~g} \%)$, somatic cells -285 of the TC/ML, which corresponded to the breeds of animals and the Russian quality parameters for the "high-class" milk category.

\section{Conclusions}

A promising direction for the selection of a north population of the dairy cattle of Ayrshire breed is defined by the individual selection of bull-producers to improve the scoring of groups of characteristics: "leg quality"- to improve by $1.2 \ldots 2.7$ points, "quality of udder"- to improve by $0.4 \ldots$ 2.9 points, with these signs prepotent ability of bulls to improve the signs it is desirable to have a standard deviation of 1.5-2.0.

\section{References}

1. Trukhachev V.I., Oleinik S.A., Zlydnev N.Z., Morozov V.Yu. Application of the recommendations of the international committee for animal recording (ICAR) in assessing the yields of dairy cattle in Russia. Research Journal of Pharmaceutical, Biological and Chemical Sciences. 2015;6(6), pp. 1314-1316.

2. Trukhachev V.I., Zlydnev N.Z., Oleinik S.A., Morozov V.Yu. Evaluation perspective directions to improvement selection traits dairy cattle of North Caucasus Ayrshire breed. Research Journal of Pharmaceutical, Biological and Chemical Sciences. 2016;7(3), pp. 2358-2359.

3. Sadovoy, V., Omarov, R., Shlykov, S., Shchedrina, T. Assessment compliance of qualitative food characteristics to standard requirements. 15th International Scientific Conference on Engineering for Rural Development, May 25-27, 2016, Jelgava, Latvia, pp. 360-363. 